\title{
Prestação de Contas em Câmaras Municipais por meio da Gestão de Custos como Incentivo à Accountability
}

\author{
Fabiano Maury Raupp \\ Doutor em Administração pela Universidade Federal da Bahia - UFBA \\ Professor da Universidade do Estado de Santa Catarina - UDESC \\ Av. Madre Benvenuta, 2037 Itacorubi, Florianopolis/SC. CEP: 88035-001 \\ E-mail: fabianoraupp@hotmail.com \\ José Antônio Gomes Pinho \\ Doutor em Regional Planning, University of London - RU \\ Professor da Universidade Federal da Bahia - UFBA \\ Av. Reitor Miguel Calmon, s/n Vale do canela, Salvador/BA. CEP: 40110-100 \\ E-mail: jagp@ufba.br
}

\section{RESUMO}

O artigo discute o processo de prestação de contas dos gastos de câmaras municipais por meio da gestão de custos, como forma de incentivar a construção da accountability. A pesquisa é do tipo exploratório, realizada por meio de um estudo de caso com abordagem quali-quantitativa. A coleta de dados deu-se por meio de entrevistas semi-estruturadas e documentos primários. $\mathrm{Na}$ análise dos dados foram utilizadas as técnicas da análise documental e descritiva. A apuração dos gastos públicos e sua prestação de contas são importantes instrumentos de controle social, permitindo aos diferentes usuários a avaliação da eficiência dos serviços prestados. As informações publicadas em murais ou encaminhadas a outros órgãos possivelmente não permitem clareza ou mesmo entendimento aos cidadãos que não possuem conhecimentos relacionados à Contabilidade Pública. Ademais, são muito condensadas, o que não permite, por exemplo, uma análise detalhada dos gastos da Câmara. A gestão de custos na Câmara Municipal possibilita uma análise das matérias cuja votação e discussão mais consomem recursos do orçamento, além de promover o controle dos gastos e identificar possíveis desperdícios. A publicação de tais informações por meio de relatórios simplificados poderá incentivar o exercício da prestação de contas e a construção da accountability.

Palavras-chave: Prestação de Contas. Câmaras Municipais. Gestão de Custos. Accountability.

\section{Accountability in Local Councils through the Management Costs}

\section{ABSTRACT}

The article discusses the process of accountability for expenditures of municipal councils through cost management as a way to encourage the construction of this practice. The research was exploratory, conducted through a case study with qualitative and quantitative approach. Data collection was done through semi- 
structured interviews and primary documents. For the data analysis, a documental and descriptive analysis was applied. The assessment of public expenditures and their accountability are important instruments of social control, allowing different users to evaluate the efficiency of the services provided. It is known that the information currently available, published on the walls or forwarded to other branches, don't give clarity or understanding to the citizens who do not known anyone related to public accounting. Moreover, the information are very condensed, which does not allow, for example, a detailed analysis of the City Council expenses. Cost management in this branch will allow an analysis of the matters whose voting and discussion demands more budget resources, and will also promote the spending control and identify potential waste. The publicity of such information through simplified reports may encourage the construction of accountability and its practice.

Key Words: Accountability. City Council. Cost Management

\section{INTRODUÇÃO}

O termo accountability é, atualmente, um dos mais citados na agenda política de diferentes países. Coloca-se em discussão o desenvolvimento de formas não eleitorais de accountability; as falhas e os acertos da accountability democrática; maneiras de amenizar as falhas e de aperfeiçoar os acertos; bem como a inserção do conceito na sociedade em termos culturais (MAINWARING, 2003).

É dever de todo poder público ser transparente e prestar contas à sociedade civil, bem como ser responsabilizado pelos atos praticados. $\mathrm{Na}$ análise do processo de prestação de contas, justificam-se as informações prestadas que vão além daquelas exigidas pela lei. O conteúdo dos relatórios que compõem a prestação de contas deve ser acessível ao cidadão, contendo clareza e objetividade nas informações disponibilizadas.

O artigo objetiva discutir o processo de prestação de contas dos gastos de câmaras municipais por meio da gestão de custos como forma de incentivar a construção da accountability. Inicialmente, faz-se uma breve incursão teórica nos fundamentos da accountability, prestação de contas e necessidade de gerenciamento dos gastos públicos. Na sequência, aborda-se o método de pesquisa utilizado. Em seguida é descrito o caso empírico, bem como os resultados alcançados na pesquisa. Por fim, são apresentadas as conclusões seguidas das referências. 


\section{REFERENCIAL TEÓRICO}

\subsection{Accountability}

Segundo Campos (1990), accountability não possui uma expressão equivalente em português que contemple o espectro de significados existentes no termo em inglês. É praticamente um lugar-comum observar que accountability não possui tradução precisa para o português (e para outras línguas neolatinas) e, daí, extrair conjecturas sobre a qualidade de nossas democracias em comparação com as anglo-saxãs (MIGUEL, 2005).

O conceito de accountability tornou-se parte dos discursos políticos, porém pouco se sabe sobre ele. Faz-se necessário, então, lembrar que a atuação na esfera pública de governo requer a preocupação com os mecanismos que a sociedade tem disponíveis para a cobrança ou a responsabilização dos agentes na ação estatal, o que se pode chamar de cidadania (BARACCHINI, 2002).

Behn (1998) enfatiza que a análise do conceito de accountability deve ser precedida de respostas para algumas indagações como: "accountability perante quem? Para quê? De que forma? Como exatamente podemos exigir accountability do governo? De fato, empregamos a frase "cobrar accountability do governo" como se seu significado fosse óbvio. Porém, como iremos cobrar accountability de quem e por quê?

Para Pereira (1997), a perspectiva patrimonialista, que confunde o patrimônio público com o do indivíduo ou de sua família, ou, ainda, de uma visão corporativista, que confunde o patrimônio do Estado com o dos grupos de interesse corporativamente organizados, faz emergir o conceito de accountability.

A accountability não emerge por si só, ou seja, é determinada por uma relação entre o Estado e a sociedade, propiciada pelo desenvolvimento democrático. É resultado de um desenvolvimento político que confere ao cidadão um papel ativo de sujeito, guardião de seus direitos (CAMPOS, 1990). A accountability não é um predicado dos sujeitos, ao contrário, é um atributo do sistema político que se impõe aos agentes públicos (CENEVIVA; FARAH, 2006). 
A accountability, em termos sintéticos e aproximativos, pode ser pensada como a transparência, o engajamento do poder público com a prestação de contas, e também a responsabilização de seus atos (Pinho; Sacramento, 2008). O conceito de accountability, conforme Akutsu e Pinho (2002), contempla duas partes: "a primeira delega responsabilidade para que a segunda proceda à gestão dos recursos; ao mesmo tempo, gera a obrigação daquele que administra os recursos de prestar contas de sua gestão, demonstrando o bom uso desses recursos".

Campos (1990) afirma que a accountability começou a ser entendida como questão de democracia, ou seja, quanto mais avançado o estágio democrático, maior o interesse pela accountability. A accountability governamental tende a acompanhar o avanço de valores democráticos, tais como igualdade, dignidade humana, participação, representatividade.

A accountability pode ser empregada, segundo Pereira (1997), para indicar a transparência governamental e a prestação de contas por parte dos gestores públicos, ou ainda para expressar a manifestação de cidadãos ou setores da sociedade civil por insatisfação quanto às ações desempenhadas por estes gestores.

Mota (2006) entende que a partir do momento em que nasce um cidadão que efetivamente pode participar da coisa pública, é que serão estabelecidas demandas por accountability. Ao considerar a accountability como um instrumento de controle da soberania popular sobre os atos dos representantes eleitos e dos agentes públicos em geral, algumas concepções do conceito de representação não serão compatíveis como o exercício da accountability.

Loureiro e Abrucio (2004) entendem por "accountability ou responsabilização um processo institucionalizado de controle político estendido no tempo (eleição e mandato) e no qual devem participar, de um modo ou de outro, os cidadãos organizados politicamente". Destacam ainda a necessidade de regras e arenas nas quais a accountability pode ser exercida, bem como práticas de negociação ampliadas entre os atores, a fim de tornar mais públicas e legítimas as decisões tomadas. Para Menezes (2006), a responsabilização dos gestores relaciona-se a decisão tomada, sua implementação, a necessidade de prestação de contas tanto de suas ações como 


\section{Prestação de Contas em Câmaras Municipais por meio da Gestão de Custos como Incentivo à}

Fabiano Maury Raupp, José Antônio Gomes Pinho

de suas omissões, e a idéia de transparência na condução das ações do poder público.

Mota (2006) infere que a accountability é uma forma de controle do poder com a natureza jurídica, uma relação obrigacional objetiva extra-contratual que força os agentes encarregados da administração de interesses públicos a explicar seus atos discricionários. Representa um instrumento que conduz à representação, pois coage os representantes a agirem no melhor interesse público. A accountability, segundo Miguel (2005), refere-se a capacidade que os constituintes têm de impor sanções aos diferentes atores do poder público, notadamente reconduzindo ao cargo aqueles que desempenham bem sua missão e destituindo os que possuem desempenho insatisfatório".

Para o CLAD (2000), a accountability é um conceito mais amplo, que inclui a existência de condições para os cidadãos participarem da definição e avaliação das políticas públicas, premiando ou punindo os responsáveis. Ela assume um caráter retrospectivo, ou seja, significa que haverá uma avaliação popular das ações passadas e que os representantes não podem, sem sérias conseqüências, afastar-se dos interesses e opiniões daqueles que constituem a suposta soberania das democracias (ARATO, 2002). Sua concepção é basicamente, bidimensional: envolve capacidade de resposta e capacidade de punição (answerability e enforcement) (CARNEIRO; COSTA, 2001).

Um modelo de accountability política, de caráter ideal, deve contemplar os seguintes pontos: a) a representação seria unicameral e não haveria o federalismo; b) o regime político não poderia ser de coalizão; c) os prazos eleitorais seriam mais curtos, com facilidade de dissolução da legislatura e inexistência de limites de reeleição, ou seja, regime parlamentar; d) o fim das contribuições privadas para os partidos políticos; e) o novo constitucionalismo, com possibilidades de mudanças constitucionais com menor rigidez e, inclusive, eleições para os juízes. No nível do modelo institucional, a accountability deve ser complementada por instituições de deliberação, constitucionalismo e representatividade descritiva. No entanto, a précondição mais importante para que um sistema de accountability realmente funcione é 
a atividade dos cidadãos nos fóruns públicos democráticos e na sociedade civil (ARATO, 2002).

Ceneviva (2006) faz um balanço teórico das principais discussões acerca desta temática. Primeiramente, a gênese da noção de accountability é bastante discutida. Uma segunda pendência teórica entre os autores que se debruçaram sobre o tema refere-se ao objeto dos mecanismos de accountability. Uma terceira fonte de discordância analítica refere-se à capacidade de sanção por parte dos mecanismos e agentes de accountability. Uma quarta área de disputa conceitual relaciona-se à discussão da restrição dos mecanismos de accountability àqueles adequados às relações de tipo: agente - principal. Um quinto campo de discussão refere-se aos atores que podem exercer o papel de agentes de accountability.

Ao observar as reformas políticas, sociais e institucionais, ocorridas no Brasil nesses últimos vinte anos, constata-se que, embora muitos passos importantes tenham sido dados em direção à accountability, com criação de novas instituições, fortalecimento institucional em geral, a caminhada promete ser longa, principalmente porque ficou caracterizado que no Brasil o surgimento de um novo valor não necessariamente implica na extinção do tradicional (PINHO; SACRAMENTO, 2008).

\subsection{Prestação de contas}

O estudo da accountability reveste-se de fundamentos como transparência, prestação de contas, participação e responsabilização dos diferentes poderes públicos pelos seus atos (PINHO; IGLESIAS; SOUZA, 2006). Como ingrediente básico da accountability, capaz de proporcionar a criação de maiores condições de confiança entre os atores do poder público e a sociedade civil, o seu exercício requer condições para que haja a disponibilidade de informações sobre a atuação dos governos e seus resultados, bem como a existência de instituições que permitam contestar as ações do poder público. O controle é um dos componentes básicos da accountability, haja vista que não há efetivação desta sem a utilização de instrumentos institucionais de controle (PÓ; ABRUCIO, 2006). 


\section{Prestação de Contas em Câmaras Municipais por meio da Gestão de Custos como Incentivo à}

Fabiano Maury Raupp, José Antônio Gomes Pinho

Behn (1998, p.39) aduz que "os sistemas tradicionais de accountability foram desenhados para estabelecer e reforçar a confiança pública na probidade do governo. Agora precisamos de um novo sistema de accountability que estabeleça e reforce a confiança pública no desempenho governamental".

A accountability supõe a obrigação de prestar contas, o que implica a possibilidade de sanção e compõe um subconjunto do repertório de práticas de controle interinstitucional e social (LAVALLE; CASTELLO, 2008). Há que se considerar que, diante de um Estado que ainda possui características patrimonialistas, em seu arranjo político não está presente a idéia de uma cidadania plena e os agentes públicos se sentem desobrigados a fazer prestação de contas à sociedade (AKUTSU; PINHO, 2002).

A qualidade e a quantidade de informação posta à disposição dos cidadãos para que julguem as ações do governo podem ser melhoradas mediante inovações institucionais, de instituições independentes de outros órgãos do governo, e que ofereçam aos cidadãos a informação necessária para que aperfeiçoem sua avaliação, a posteriori, dos atos do governo, não apenas dos resultados (Przeworski, 1998).

A prestação de contas deve ir além daquelas exigidas por lei, ou seja, as contas públicas disponibilizadas por força da lei não podem ser compreendidas como exemplo de accountability. Os relatórios publicados precisam ser acessíveis ao cidadão comum, não apenas no sentido da facilidade ao link destes relatórios, mas também que eles sejam claros e objetivos aos dispor a informação financeira (AMARAL, 2007).

Contudo, os relatórios normalmente exigidos pela legislação contemplam uma linguagem pouco acessível aos cidadãos, prejudicando o entendimento do seu conteúdo. Acredita-se que a adoção de uma gestão de custos por parte do ente público, além de propiciar um gerenciamento dos gastos, poderá alavancar o processo de prestação de contas, bem como incentivar a construção da accountability. 


\subsection{Gestão dos gastos públicos}

Para Alonso (1999), a crise fiscal do Estado e a exposição dos mercados domésticos à competição internacional impuseram a necessidade de uma reforma do Estado que privilegiasse a qualidade do gasto público. Diferentemente do setor privado, no setor público as preocupações com a gestão de custos não estão relacionadas com a avaliação de estoques ou com a apuração de lucros, mas sim com o desempenho dos serviços públicos. A melhoria no desempenho de uma organização governamental requer sistemas de informações gerenciais que dêem sustentação ao seu processo decisório.

O próprio arcabouço legal já destaca em seus diversos textos a necessidade de gerenciamento dos gastos públicos. De acordo com a Lei $n^{\circ} 4.320 / 1964$, há a necessidade de informações de custos já na elaboração da proposta orçamentária:

Art. 22. A proposta orçamentária, que o Poder Executivo encaminhará ao Poder Legislativo, nos prazos estabelecidos nas Constituições e nas Leis Orgânicas dos Municípios, compor-se-á de:

(...)

IV - Especificação dos programas especiais de trabalho custeados por dotações globais, em termos de metas visadas, decompostas em estimativas do custo das obras a realizar e dos serviços a prestar, acompanhada de justificação econômica, financeira, social e administrativa.

(...)

Art. 85. Os serviços de contabilidade serão organizados de forma a permitirem - acompanhamento da execução orçamentária, o conhecimento da composição patrimonial, a determinação dos custos dos serviços industriais, o levantamento dos balanços gerais, a análise e a interpretação dos resultados econômicos e financeiros.

Já o Decreto № 2.829, de 29 de outubro de 1998, ao estabelecer normas para a elaboração e execução do Plano Plurianual e dos Orçamentos da União, apresenta a necessidade de gerenciamento que compreenda os custos dos programas:

Art. 4ำ Será adotado, em cada Programa, modelo de gerenciamento que compreenda:

(...)

II - controle de prazos e custos.

As necessidades destacadas na Lei $n^{\circ} 4.320 / 1964$ e no Decreto ํㅜㄹ 2.829/1998 foram reforçadas pela Lei Complementar $n^{\circ}$ 101/2000 (Lei de Responsabilidade Fiscal), quando traz em seu art. 50: 
Art. 50. Além de obedecer às demais normas de contabilidade pública, a escrituração das contas públicas observará as seguintes:

$(\ldots)$

§ 30 A Administração Pública manterá sistema de custos que permita a avaliação e o acompanhamento da gestão orçamentária, financeira e patrimonial.

Para Ribeiro Filho (2001), esse dispositivo da LRF ampliou "de forma significativa o escopo previsto na Lei no 4.320/64, que trata apenas dos serviços públicos industriais". De forma análoga, Cruz e Platt (2001) comentam que "a exigência de controle de custos e avaliação dos resultados, a partir do art. 50 da Lei Complementar 101, cria uma nova perspectiva para a aplicação da contabilidade de custos". Apesar da necessidade de gestão dos gastos públicos, Duarte (2002) apresenta algumas causas para esta incipiente gestão: despreocupação dos administradores em relação à matéria; carência de pessoal especializado em custos na esfera pública; deficiências do sistema de controle interno dos executivos municipais; reduzida oferta no meio acadêmico e no mercado de estudos técnicos e cursos de treinamento; escassa disponibilidade de recursos que contribui para o desinteresse dos administradores municipais na contratação de assessoria especializada visando à implantação de um sistema de gestão de custos.

\section{MÉTODO}

A preocupação com o conhecimento da realidade é uma constante na vida do homem. A pesquisa apresenta-se como uma forma de investigação que tem como finalidade buscar respostas às indagações da sociedade, através de procedimentos científicos. Os seus delineamentos possuem um importante papel na pesquisa científica, no sentido de articular planos e estruturas a fim de obter respostas para os problemas de estudo.

Os delineamentos desta pesquisa deram-se em função dos objetivos, dos procedimentos e da abordagem do problema. No que diz respeito aos objetivos, a pesquisa consiste de um estudo do tipo exploratório; em relação aos procedimentos, 
refere-se a uma pesquisa do tipo estudo de caso e documental; e quanto à abordagem do problema utilizou-se a abordagem quali-quantitativa.

Para coletar os dados foram utilizadas entrevistas semi-estruturadas e documentos primários. As entrevistas foram realizadas com os funcionários e os agentes políticos. Os documentos primários analisados referem-se aos registros contábeis cujo acesso foi permitido. As técnicas utilizadas no processo de análise dos dados foram: análise descritiva e análise documental. Estas técnicas são amplamente empregadas nas Ciências Sociais, em virtude de diversos trabalhos nesta área demandarem uma abordagem quali-quantitativa.

\subsection{Objeto de Estudo}

A Câmara Municipal objeto de estudo representa o Poder Legislativo do Município de Paulo Lopes. Tal município, localizado em Santa Catarina, foi criado em 21 de dezembro de 1961 por desmembramento do município de Palhoça. Segundo o IBGE (2007), possui aproximadamente 6.830 habitantes.

A escolha da Câmara do município de Paulo Lopes, como objeto de estudo, deve-se ao fato de que Paulo Lopes é um município bem típico e representativo de um conjunto de municípios de Santa Catarina que possuem um mesmo quadro de condições estruturais (limitação de recursos e falta de equipes treinadas).

Empreendeu-se uma pesquisa no âmbito do Legislativo considerando que os estudos são realizados, normalmente, com o Executivo, como nos trabalhos de Duarte (2002), Alves Filho e Martinez (2006), Rêgo, Barbosa e Araújo (2007), Corbari et al. (2007), Gerikg et al. (2007), Souza (2008), Mauss e Souza (2008).

É um município de colonização açoriana e suas principais atividades econômicas são a agricultura e a pesca. Paulo Lopes tem bom potencial turístico, mas ainda é preciso desenvolver a infra-estrutura. A pequena arrecadação obriga o município a depender dos recursos do FPM (Fundo de Participação dos Municípios).

A Câmara Municipal foi instalada aos trinta e um dias do mês de janeiro de 1963, com a diplomação de sete vereadores. Atualmente, conta com nove vereadores. O quadro de colaboradores é formado por cinco funcionários, sendo um contador, um 
assessor técnico legislativo, uma assessora parlamentar, uma auxiliar de serviços gerais e uma estagiária.

As instalações físicas são alugadas, haja vista que não possui prédio próprio. A reunião dos vereadores para discussão e votação das matérias acontece uma vez por semana. O atendimento ao público ocorre de segunda-feira a sexta-feira, das 07h00min às 13 h00min. O Regimento Interno da Câmara contempla os produtos apresentados no Quadro 1 como passíveis de discussão e votação.

Quadro 1: Produtos da entidade objeto de estudo

\begin{tabular}{|c|c|}
\hline Produtos & Descrição \\
\hline Projeto de Lei & $\begin{array}{c}\text { Proposição que tem por finalidade a regulamentação de matéria de âmbito } \\
\text { municipal, sujeita à sanção do Poder Executivo. }\end{array}$ \\
\hline Decreto Legislativo & $\begin{array}{l}\text { Proposição destinada a regular matéria de exclusiva competência da Câmara } \\
\text { Municipal, com efeito normativo em toda a municipalidade. }\end{array}$ \\
\hline $\begin{array}{l}\text { Projeto de } \\
\text { Resolução }\end{array}$ & $\begin{array}{c}\text { Proposição que se destina a regular matéria de competência exclusiva da } \\
\text { Câmara Municipal, de natureza político-administrativa. }\end{array}$ \\
\hline Codificação & $\begin{array}{l}\text { São projetos de codificação: Código - é a reunião de disposições legais sobre } \\
\text { a mesma matéria, visando estabelecer os princípios gerais do sistema e } \\
\text { prover corretamente a matéria tratada; Consolidação - é a reunião de } \\
\text { diversas leis em vigor sobre o mesmo assunto; Estatuto ou regimento - é o } \\
\text { conjunto de normas disciplinares fundamentais que rege a atividade de um } \\
\text { órgão ou de uma entidade. }\end{array}$ \\
\hline Indicação & $\begin{array}{c}\text { Proposição em que o autor sugere medidas de interesse púbicos aos órgãos } \\
\text { competentes. }\end{array}$ \\
\hline Moção & $\begin{array}{l}\text { Proposição em que a Câmara Municipal manifesta a sua posição, de apoio ou } \\
\text { de oposição, a respeito de determinado assunto de interesse público. }\end{array}$ \\
\hline Requerimento & $\begin{array}{c}\text { Pedido verbal ou escrito, dirigido ao presidente da Mesa Diretora, sobre } \\
\text { assunto de interesse do autor. }\end{array}$ \\
\hline Substitutivo & $\begin{array}{l}\text { Projeto apresentado para substituir outro já em tramitação, sobre a mesma } \\
\text { matéria. }\end{array}$ \\
\hline Emenda & Modificação apresentada a determinado dispositivo de matéria em tramitação. \\
\hline $\begin{array}{l}\text { Julgamento de } \\
\text { Contas }\end{array}$ & Julgar as contas da administração municipal, direta e indireta. \\
\hline
\end{tabular}

Fonte: Câmara Municipal de Paulo Lopes, 1994.

Dentre os produtos apresentados no Quadro 1, a Codificação e o Substitutivo raramente são discutidos e votados. O Julgamento de Contas acontece, normalmente, uma vez no ano, quando a Câmara recebe do Tribunal de Contas do Estado de Santa Catarina as contas da Prefeitura Municipal, referente ao exercício anterior, para discussão e votação. As demais matérias acontecem regularmente durante o ano, com destaque para os Projetos de Lei e Indicações. 
No tocante à prestação de contas, a Câmara encaminha ao Executivo Municipal, mensalmente e anualmente, os relatórios contábeis exigidos pela Lei $\mathrm{n}^{\circ}$ 4.320/1964 e pela Lei Complementar $n^{\circ}$ 101/2000. As versões quadrimestral e semestral desses relatórios são publicadas no mural instalado nas dependências da Câmara. Para o Tribunal de Contas do Estado de Santa Catarina é encaminhada, bimestralmente, por meio do Sistema de Fiscalização Integrada de Gestão - e-Sfinge, toda a movimentação contábil. Ao Ministério da Previdência Social são enviadas, mensalmente, por meio do Sistema Empresa de Recolhimento do FGTS e Informações à Previdência Social - SEFIP, informações relativas ao recolhimento do INSS. Ao Ministério do Trabalho e Emprego é encaminhada, anualmente, por meio da Relação Anual de Informações Sociais - RAIS, informações sobre a atividade trabalhista na organização. Para a Receita Federal é encaminhada semestralmente a Declaração de Débitos e Créditos Tributários Federais - DCTF e, anualmente, a Declaração de Imposto de Renda Retido na Fonte - DIRF.

\section{RESULTADOS}

\subsection{Identificação dos gastos}

As contas mais utilizadas para a contabilização dos gastos são: salário-família; vencimentos e vantagens fixas; obrigações patronais; indenizações e restituições trabalhistas; diárias; auxílio financeiro a estudantes; material de consumo; outros serviços de terceiros - pessoa física; outros serviços de terceiros - pessoa jurídica; e equipamentos e material permanente. Na seqüência, apresenta-se uma breve descrição dos gastos lançados nestas contas:

- Salário-família: benefício pago aos trabalhadores com salário mensal para auxiliar no sustento dos filhos de até 14 anos incompletos ou inválidos;

- Vencimentos e vantagens fixas: compreende gastos relacionados ao vencimento e remuneração devidos aos funcionários e vereadores;

- Obrigações patronais: refere-se ao valor da obrigação patronal incidente sobre a folha de pagamento dos funcionários e vereadores e devida à Previdência Social; 
- Indenizações e restituições trabalhistas: compreende gastos referentes à exoneração de funcionários e o valor pago ao Presidente da Câmara no montante de $50 \%$ sobre a remuneração devida aos vereadores, para exercer as funções de representação;

- Auxílio alimentação: auxílio alimentação em pecúnia, concedido aos funcionários e agentes políticos;

- Diárias: valores concedidos a funcionários e vereadores em razão de deslocamento a serviço do município ou para participarem de eventos;

- Auxílio financeiro a estudantes: auxílio concedido para reembolsar parte da mensalidade paga pelo funcionário para realizar curso superior;

- Passagens para o país: passagens e despesas com locomoção para participação em eventos;

- Material de consumo: gastos relacionados ao material de expediente, material de limpeza e, eventualmente, gêneros alimentícios;

- Outros serviços de terceiros - pessoa física: compreende gastos com locação das instalações e valores pagos a terceiros para prestação de serviços relacionados a pequenos reparos nas instalações do prédio;

- Outros serviços de terceiros - pessoa jurídica: gastos com a fatura de telefone móvel, fatura de telefone fixo, fatura de energia elétrica, postagem de documentos, e aluguel do sistema de contabilidade pública;

- Equipamentos e material permanente: valores relacionados à aquisição de equipamentos e material permanente.

A Câmara apresentou um gasto total de $R \$ 400.283,20$ no exercício de 2008 , objeto de estudo. Deste total, $\mathrm{R} \$ 8.159,95$ devem ser classificados como investimentos já que, segundo Martins (2003), são gastos ativados em função da vida útil ou benefícios atribuíveis a futuros períodos.

No conjunto de gastos, $\mathrm{R} \$ 392.123,25$ devem ser classificados como custo do período, haja vista que, de acordo com Martins (2003), refere-se a gastos utilizados na produção de bens ou serviços.

Além dos custos mencionados, a organização poderia ter custos relacionados à depreciação de equipamentos e material permanente. Por meio de análise dos 
registros contábeis, percebeu-se que a maioria dos equipamentos e materiais permanentes já se encontra totalmente depreciada, restando uma parcela ínfima a ser depreciada. Tal situação motivou a não consideração deste tipo gasto.

\subsection{Proposta de Centros de Custos}

A Câmara não possui divisão de sua estrutura em centros de custos. Assim, fez-se uma proposição de divisão em que o agrupamento em centros de custos considerou as afinidades entre os setores, bem como os serviços desenvolvidos por eles.

A apuração de custos proposta nesse estudo ocorre por meio dos seguintes centros de custos: centros de custos auxiliares (Contábil, Serviços Gerais); centros de custos produtivos (Jurídico e Parlamentar, Comissões). O contador atua no centro de custos Contábil; a auxiliar de serviços gerais atua no centro de custos Serviços Gerais; o assessor técnico legislativo, a assessora parlamentar e a estagiária atuam no centro de custos Jurídico e Parlamentar; os vereadores atuam no centro de custos Comissões.

\subsection{Agrupamento de Gastos em cada Centro de Custos}

Com a identificação dos gastos e a proposição de uma estrutura de centros de custos, fez-se a alocação desses gastos aos centros de custos. Alguns dos gastos foram apropriados diretamente, outros necessitaram de rateio. Os gastos por centro de custos são apresentados na Tabela 1. 


\section{Prestação de Contas em Câmaras Municipais por meio da Gestão de Custos como Incentivo à}

Fabiano Maury Raupp, José Antônio Gomes Pinho

Tabela 1: Gastos da organização no exercício de 2008 por centro de custos

\begin{tabular}{|c|c|c|c|c|c|}
\hline \multirow[b]{2}{*}{ Itens de Gastos } & \multicolumn{2}{|c|}{ Centros Auxiliares } & \multicolumn{2}{|c|}{ Centros Produtivos } & \multirow[b]{2}{*}{ Total } \\
\hline & 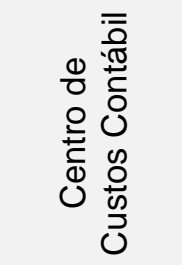 & 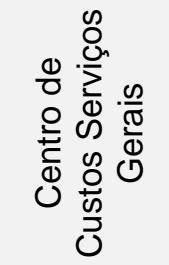 & 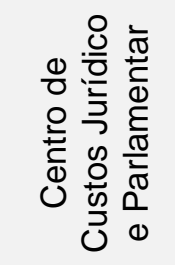 & 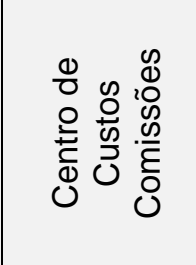 & \\
\hline \multicolumn{6}{|c|}{ Custos Diretos } \\
\hline Salário-família & 0,00 & 572,32 & 0,00 & 0,00 & 572,32 \\
\hline Vencimentos e vantagens fixas & $24.233,27$ & $5.646,50$ & $25.112,29$ & $190.235,10$ & $245.227,16$ \\
\hline Obrigações patronais & $5.331,32$ & $1.242,23$ & $5.524,70$ & $44.581,86$ & $56.680,11$ \\
\hline Indenizações e restituições & 0,00 & 0,00 & $1.546,49$ & $14.207,93$ & $15.754,42$ \\
\hline Auxílio alimentação & 900,00 & 900,00 & $2.600,00$ & $10.100,00$ & $14.500,00$ \\
\hline Diárias & 800,00 & 0,00 & 200,00 & $7.200,00$ & $8.200,00$ \\
\hline Auxílio financeiro a estudantes & 0,00 & 960,00 & 0,00 & 0,00 & 960,00 \\
\hline Passagens para o país & 0,00 & 0,00 & 0,00 & $3.901,96$ & $3.901,96$ \\
\hline Subtotal & $31.264,59$ & $9.321,05$ & $34.983,48$ & $270.226,85$ & $345.795,97$ \\
\hline \multicolumn{6}{|c|}{ Custos Indiretos } \\
\hline Material de consumo & 459,09 & 136,87 & 513,70 & $3.968,03$ & $5.077,69$ \\
\hline Outros serviços de terceiros - PF & $1.693,44$ & 504,87 & $1.894,88$ & $14.636,81$ & $18.730,00$ \\
\hline Outros serviços de terceiros - PJ & $2.036,07$ & 607,02 & $2.278,26$ & $17.598,24$ & $22.519,59$ \\
\hline Subtotal & $4.188,60$ & $1.248,76$ & $4.686,84$ & $36.203,08$ & $46.327,28$ \\
\hline Total & $35.453,19$ & $10.569,81$ & $39.670,32$ & $306.429,93$ & $392.123,25$ \\
\hline
\end{tabular}

Fonte: Dados da pesquisa.

Os gastos com Salário-família foram alocados diretamente ao centro de custos Serviços Gerais, por tratar-se de um encargo concedido somente à funcionária que trabalha neste centro. Os gastos com Vencimentos e vantagens fixas e Obrigações patronais também foram alocados diretamente aos centros de custos por meio de análise da folha de pagamento.

A alocação direta também foi utilizada para os gastos com Indenizações e restituições trabalhistas, Auxílio alimentação e Diárias. Tais alocações foram possibilitadas pela análise dos registros contábeis. Os gastos com Auxílio financeiro a estudantes referem-se aos valores concedidos para reembolsar parte da mensalidade paga pela auxiliar de serviços gerais para realizar curso superior.

$\mathrm{Na}$ alocação dos custos indiretos, a escolha do critério de rateio levou em consideração a representatividade dos custos indiretos em relação aos custos diretos e as características internas de utilização. Decidiu-se adotar um critério único de rateio 
Prestação de Contas em Câmaras Municipais por meio da Gestão de Custos como Incentivo à

Fabiano Maury Raupp, José Antônio Gomes Pinho

para os custos indiretos, utilizando-se o percentual de custos diretos que cada centro de custos recebeu.

\subsection{Alocação dos Gastos dos Centros de Custos Auxiliares aos Produtivos}

A alocação dos gastos dos centros de custos auxiliares aos produtivos foi feita mediante alocação seqüencial. Neste processo, os gastos do centro de custos Contábil são alocados ao centro de custos Serviços Gerais e aos centros de custos produtivos. Os gastos do centro de custos Serviços Gerais e a parcela recebida do centro de custos Contábil são alocados aos centros de custos produtivos. Os resultados obtidos a partir das alocações são demonstrados na Tabela 2.

Tabela 2: Alocação dos gastos dos centros de custos auxiliares aos produtivos

\begin{tabular}{|c|c|c|c|c|c|}
\hline \multirow[b]{2}{*}{ Itens de Gastos } & \multicolumn{2}{|c|}{ Centros Auxiliares } & \multicolumn{2}{|c|}{ Centros Produtivos } & \multirow[b]{2}{*}{ Total } \\
\hline & 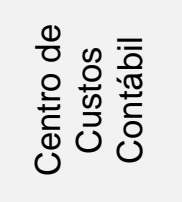 & 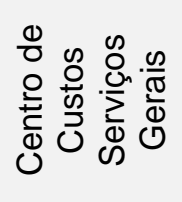 & 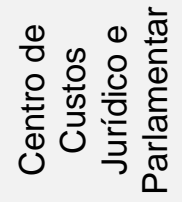 & 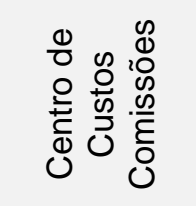 & \\
\hline Total de cada centro de custos & $35.453,19$ & $10.569,81$ & $39.670,32$ & $306.429,93$ & $392.123,25$ \\
\hline Rateio dos gastos (Contábil) & --- & $1.772,66$ & $1.772,66$ & $31.907,87$ & $35.453,19$ \\
\hline Rateio dos gastos (Serviços Gerais) & --- & --- & 617,12 & $11.725,35$ & $12.342,47$ \\
\hline Total de cada centro produtivo & & & $42.060,10$ & $350.063,15$ & 392.123 .25 \\
\hline
\end{tabular}

Fonte: Dados da pesquisa.

$\mathrm{Na}$ alocação dos gastos do centro de custos Contábil foi estimado o volume de serviços que este centro presta aos outros centros. A partir de uma entrevista com o profissional que atua diretamente neste centro, aliada a análise de registros contábeis, definiu-se os seguintes percentuais de prestação de serviços: 5\% para o centro de custos Serviços Gerais; 5\% para o centro de custos Jurídico e Parlamentar; e 90\% para o centro de custos Comissões. Tais percentuais foram utilizados na alocação dos custos do centro Contábil.

Procedimento semelhante foi utilizado para alocar o total de gastos do centro de custos Serviços Gerais aos centros produtivos. Também foi estimado o volume de serviços prestados por este centro, o qual foi definido em percentuais por meio de uma 
entrevista aplicada à funcionária que atua neste centro. Foram definidos os seguintes percentuais de prestação de serviços: $5 \%$ para o centro de custos Jurídico e Parlamentar; e 95\% para o centro de custos Comissões. Estes percentuais foram utilizados para alocação dos custos do centro de Serviços Gerais aos demais centros.

Após a alocação dos gastos dos centros de custos auxiliares aos produtivos, o total de gastos da Câmara Municipal, num montante de $\mathrm{R} \$ 392.123,25$, está dividido entre o centro de custos Jurídico e Parlamentar $(R \$ 42.060,10)$ e o centro de custos Comissões $(\mathrm{R} \$ 350.063,15)$.

\subsection{Alocação dos Gastos dos Centros de Custos Produtivos aos Produtos}

A alocação dos gastos dos centros de custos produtivos aos produtos considerou o tempo utilizado na confecção, discussão e votação dos mesmos. Alguns produtos são confeccionados, discutidos e votados na Câmara Municipal (Decreto Legislativo, Projeto de Resolução, Indicação, Moção, Requerimento, Emenda), enquanto outros são confeccionados na Prefeitura Municipal e discutidos e votados na Câmara Municipal (Projeto de Lei, Substitutivo, Prestação de Contas).

Em uma tentativa de criar parâmetros de mensuração de tempos para a realização dos produtos, foram estabelecidos pesos a partir do tempo utilizado para confeccioná-los, discuti-los e votá-los. O estabelecimento de pesos foi feito em conjunto com profissionais envolvidos no processo (vereadores, assessora parlamentar e assessor técnico legislativo). Os produtos e seus respectivos pesos estão demonstrados na Tabela 3.

Tabela 3: Pesos dos produtos

\begin{tabular}{|c|c|}
\hline Produtos & Pesos \\
\hline Projetos de Lei & 3 \\
\hline Projetos de Resolução & 4 \\
\hline Indicações & 1 \\
\hline Moções & 1 \\
\hline Requerimentos & 1 \\
\hline Emendas & 2 \\
\hline Julgamento de Contas & 3 \\
\hline
\end{tabular}

Fonte: Dados da pesquisa. 
Fabiano Maury Raupp, José Antônio Gomes Pinho

Durante o exercício de 2008 foram discutidos e votados 55 Projetos de Lei e feito o Julgamento de Contas do Executivo referente ao exercício anterior. Durante 2008 foram confeccionados, discutidos e votados: 1 Projeto de Resolução, 53 Indicações, 11 Moções e 6 Requerimentos. Não houve confecção, discussão e votação de Emendas.

Com os pesos apresentados na Tabela 3 e o total de produtos votados e discutidos, apresenta-se na Tabela 4 o valor dos gastos dos centros de custos produtivos alocado aos produtos.

Tabela 4: Gastos dos centros de custos produtivos alocados aos produtos

\begin{tabular}{|c|c|c|c|}
\hline \multirow{2}{*}{ Produtos } & \multicolumn{2}{|c|}{ Centros Produtivos } & \multirow{2}{*}{ Total } \\
\cline { 2 - 3 } & $\begin{array}{c}\text { Centro de Custos } \\
\text { Jurídico e } \\
\text { Parlamentar }\end{array}$ & $\begin{array}{c}\text { Centro de Custos } \\
\text { Comissões }\end{array}$ & \\
\hline Total de cada centro produtivo & $42.060,10$ & $350.063,15$ & $392.123,25$ \\
\hline Projetos de Lei & $28.677,34$ & $238.679,42$ & $267.356,76$ \\
\hline Projetos de Resolução & 695,21 & $5.786,17$ & $6.481,38$ \\
\hline Indicações & $9.211,51$ & $76.666,72$ & $85.878,23$ \\
\hline Moções & $1.911,82$ & $15.911,96$ & $17.823,78$ \\
\hline Requerimentos & $1.042,81$ & $8.679,25$ & $9.722,06$ \\
\hline Emendas & 0,00 & 0,00 & 0,00 \\
\hline Julgamento de Contas & 521,41 & $4.339,63$ & $4.861,04$ \\
\hline
\end{tabular}

Fonte: Dados da pesquisa.

O cálculo do custo unitário é obtido a partir da divisão dos custos totais dos produtos, Tabela 4, pelo número de produtos discutidos e votados no ano. Na Tabela 5 apresenta-se o custo unitário de cada produto.

Tabela 5: Custo unitário de cada produto

\begin{tabular}{|c|c|}
\hline Produtos & Custo Unitário \\
\hline Projetos de Lei & $4.861,03$ \\
\hline Projetos de Resolução & $6.481,38$ \\
\hline Indicações & $1.620,34$ \\
\hline Moções & $1.620,34$ \\
\hline Requerimentos & $1.620,34$ \\
\hline Julgamento de Contas & $4.861,04$ \\
\hline
\end{tabular}

Fonte: Dados da pesquisa. 
O processo de apropriação dos custos seguiu a metodologia do custeio por absorção (com departamentalização). A partir da análise do processo de alocação dos custos na Câmara Municipal, o gestor poderá inferir sobre as matérias cuja votação e discussão mais consomem recursos do orçamento, além de promover o controle dos gastos e identificar possíveis desperdícios.

\subsection{Prestação de Contas dos Gastos}

A Câmara não possui um portal para disponibilizar e publicar informações decorrentes de suas atividades. A utilização de um portal poderia favorecer o exercício da prestação de contas e da accountability. As publicações realizadas, basicamente restritas aos relatórios contábeis exigidos pela Lei $n^{\circ} 4.320 / 1964$ e pela Lei Complementar $n^{\circ} 101 / 2000$, são feitas no próprio mural.

Sabe-se que as informações disponibilizadas, publicadas no mural ou encaminhadas a outros órgãos, não permitem clareza ou mesmo entendimento aos cidadãos que não possuem conhecimentos relacionados à Contabilidade Pública. Ademais, as informações são muito condensadas, o que não permite, por exemplo, uma análise detalhada dos gastos da Câmara.

Apesar do arcabouço legal já destacar em seus diversos textos a necessidade de gerenciamento dos gastos públicos, o desenvolvimento de modelos de gestão de custos dos serviços públicos ainda é algo incipiente. O gerenciamento de custos auxilia os gestores, responsáveis pelas finanças públicas, na análise de resultados, desempenho e eficiência dos recursos públicos.

A apuração dos gastos públicos e sua prestação de contas são importantes instrumentos de controle social, permitindo aos diferentes usuários a avaliação da eficiência dos serviços prestados. Um dos fatores impeditivos para que os sistemas de controle interno e externo possam avaliar a eficiência dos serviços públicos é justamente a inexistência de sistemas de custos (Alonso, 1999).

Percebe-se que com o sistema de informação existente o gestor da Câmara não conhece em que medida cada tipo de gasto contribui para os resultados obtidos, bem como não sabe quais atividades agregam valor ao resultado final de suas ações. Desconhece a taxa de recursos consumida pelas atividades e quanto custam os 
processos de trabalho do Legislativo, fato este que corrobora com o que preconiza Alonso (1999). Entende-se que a estruturação de uma gestão de custos e a prestação de contas dela decorrente poderá incentivar o exercício da accountability.

\section{CONCLUSÃO}

O artigo teve como objetivo discutir o processo de prestação de contas dos gastos de câmaras municipais por meio da gestão de custos como forma de incentivar a construção da accountability. A gestão de custos oferece um conjunto de informações acerca dos custos unitários das matérias discutidas e votadas no âmbito da Câmara, bem como um controle dos mesmos.

Os dados coletados junto à Câmara Municipal objeto de estudo compreenderam aspectos relacionados à identificação dos gastos, proposta de centros de custos, agrupamento de gastos de acordo com cada centro de custos, alocação dos gastos dos centros de custos auxiliares aos produtivos, alocação dos gastos dos centros de custos produtivos aos produtos, e análise da gestão de custos como forma de incentivar o exercício da prestação de contas.

Os produtos analisados compreendem a discussão e votação de Projetos de Lei, Decretos Legislativos, Projetos de Resolução, Codificações, Indicações, Moções, Requerimentos, Substitutivos, Emenda e Julgamentos de Contas.

Com a adoção do custeio por absorção (departamentalização), fez-se uma proposição de divisão da estrutura física em centros de custos. Tal agrupamento deuse por meio de afinidades entre os setores, bem como os serviços desenvolvidos, sendo eles: centros de custos auxiliares (Contábil, Serviços Gerais); e centros de custos produtivos (Jurídico e Parlamentar, Comissões).

Após a alocação dos gastos aos diferentes centros de custos e sua concentração nos centros de custos produtivos, fez-se a alocação dos custos aos produtos. Foram estabelecidos pesos para cada produto, levando em consideração o tempo utilizado para confeccioná-los, discuti-los e votá-los. O estabelecimento de pesos foi feito em conjunto com profissionais envolvidos no processo.

A gestão de custos na Câmara Municipal possibilitará ao gestor uma análise 
Prestação de Contas em Câmaras Municipais por meio da Gestão de Custos como Incentivo à

Fabiano Maury Raupp, José Antônio Gomes Pinho

das matérias cuja votação e discussão mais consomem recursos do orçamento, além de promover o controle dos gastos e identificar possíveis desperdícios. A publicação de tais informações por meio de relatórios simplificados poderá incentivar o exercício da prestação de contas e a construção da accountability.

\section{REFERÊNCIAS}

AKUTSU, Luiz; PINHO, José Antônio Gomes de. Sociedade da informação, accountability e democracia delegativa: investigação em portais de governo no Brasil. Revista de Administração Pública. Rio de Janeiro, ano 36, n.5, p.723-745, set./out. 2002.

ALONSO, Marcos. Custos nos serviços públicos. Revista do Serviço Público. Brasília, ano 50, n.1, p.37-63, jan./mar. 1999.

ALVES FILHO, Emílio Maltez; MARTINEZ, Antônio Lopo. Gestão de custos numa secretaria municipal de educação. In: CONGRESSO BRASILEIRO DE CUSTOS, XIII, 2006. Belo Horizonte. Anais... Belo Horizonte: ABC, 2006.

AMARAL, Marcelo Santos. Accountability, governo local e democracia: investigação em portais municipais do Estado da Bahia. 2007. 133f. Dissertação (Mestrado em Administração), Escola de Administração da Universidade Federal da Bahia, Núcleo de Pós-Graduação em Administração, Universidade Federal da Bahia, Salvador, 2007.

ARATO, Andrew. Representação, soberania popular e accountability. Lua Nova. São Paulo, n.55-56, p. 85-103, 2002.

BARACCHINI, Sabrina Addison. A inovação presente na administração pública brasileira. Revista de Administração de Empresas, São Paulo, v.42, n.2, p.104-109, abr./jun. 2002.

BEHN, Robert D. O novo paradigma da gestão pública e a busca da accountability democrática. Revista do Serviço Público. Brasília, ano 49, n.4, p.5-45, out./dez. 1998.

BRASIL. Decreto $n^{\circ}$ 2.829, de 29 de outubro de 1998. Estabelece normas para a elaboração e execução do Plano Plurianual e dos Orçamentos da União, e dá outras providências. Diário Oficial da República Federativa do Brasil, Brasília, de 03 de outubro de 1998.

BRASIL. Lei Complementar $n^{\circ} 101$ de 04 de Maio de 2000. Brasília, DF: Senado, 2000. 
BRASIL. Lei Federal $n^{\circ} 4.320$ de 17 de março de 1964. Estatui normas gerais de direito financeiro para elaboração dos orçamentos e balanços da União, dos Estados, dos Municípios e do Distrito Federal. Brasília, DF: Senado, 1964.

CAMPOS, Ana Maria. Accountability: quando poderemos traduzi-la para o português? Revista de Administração Pública. Rio de Janeiro, ano 24, n.2, p.30-50, fev./abr. 1990.

CARNEIRO, Carla Bronzo Ladeira; COSTA, Bruno Lazzarotti Diniz. Inovação institucional e accountability: 0 caso dos conselhos setoriais. In: CONGRESO INTERNACIONAL DEL CLAD SOBRE LA REFORMA DEL ESTADO Y DE LA ADMINISTRACIÓN PÚBLICA,VI, 2001, Buenos Aires. Anais... Buenos Aires: CLAD, 2001.

CENEVIVA, Ricardo, FARAH, Marta Ferreira Santos. Democracia, avaliação e accountability: a avaliação de políticas públicas como instrumento de controle democrático. In: ENCONTRO DE ADMINISTRAÇÃO PÚBLICA E GOVERNANÇA, II, 2006, São Paulo. Anais... Rio de Janeiro: ANPAD, 2006.

CENEVIVA, Ricardo, FARAH, Marta Ferreira Santos. Democracia, avaliação e accountability: a avaliação de políticas públicas como instrumento de controle democrático. In: ENCONTRO DE ADMINISTRAÇÃO PÚBLICA E GOVERNANÇA, II, 2006, São Paulo. Anais... Rio de Janeiro: ANPAD, 2006.

CLAD (CENTRO LATINOAMERICANO DE ADMINISTRACIÓN PARA EL DESARROLLO). La responsabilización en la nueva gestión pública latinoamericana. Buenos Aires: Eudeba, 2000.

CORBARI, Ely Célia et al. Contabilidade pública gerencial: custo por atividades e resultado econômico em Centro Municipal de Educação Infantil. In: CONGRESSO BRASILEIRO DE CUSTOS, XIV, 2007. João Pessoa. Anais... João Pessoa: ABC, 2007.

CRUZ, F., PLATT, O. A. As Exigências de Implantação de Sistema de Custos pela Lei de Responsabilidade Fiscal e a Oportunidade para o Surgimento da CEMP Contabilidade Estatal Municipal Participativa. In: SEMINÁRIO DE CONTABILIDADE DA USP, I, 2001, São Paulo. Anais... São Paulo: USP, 2001.

DUARTE, Reinaldo B. Procedimento para implantação da gestão baseada em atividades como instrumento de apoio à gestão pública municipal. 2002. $177 f$. Dissertação (Mestrado em Engenharia de Produção) - Programa de pós-Graduação em Engenharia de Produção, Universidade Federal de Santa Catarina, Florianópolis, 2002. 
Prestação de Contas em Câmaras Municipais por meio da Gestão de Custos como Incentivo à

GERIKG, Willson et al. Custos dos serviços na administração pública municipal: um estudo utilizando o método do custo-padrão. In: CONGRESSO BRASILEIRO DE CUSTOS, XIV, 2007. João Pessoa. Anais... João Pessoa: ABC, 2007.

IBGE - Instituto Brasileiro de Geografia e Estatística. Contagem 2007. Disponível em: <http://www.ibge.gov.br/home/estatistica/populacao/contagem2007>. Acesso em 07 jul. 2008.

LAVALLE, Adrian Gurza; CASTELLO, Graziela. Sociedade civil, representação e a dupla face da accountability: cidade do México e São Paulo. Caderno $\mathrm{CRH}$, Salvador, v.21, n.52, p. 67-86, jan./abr. 2008.

LOUREIRO, Maria Rita; ABRUCIO, Fernando Luiz. Política e reformas fiscais no Brasil recente. Revista de Economia Política. São Paulo, ano 24, n. 1, p.50-72, jan./mar. 2004.

MAINWARING, S. Introduction: democratic accountability in Latin America. In: MAINWARING, S.; WELNA, C. Democratic accountability in Latin America. Oxford University Press: New York, 2003.

MAUSS, Cezar Volnei; SOUZA, Marcos Antonio. Gestão de custos aplicada ao setor público: modelo para mensuração e análise da eficiência e eficácia governamental. São Paulo: Atlas, 2008.

MIGUEL, Luis Felipe. Impasses da accountability: dilemas e alternativas da representação política. Revista de Sociologia Política. Curitiba, n. 25, p. 25-38, nov. 2005.

MOTA, A. C. Y. H. de A. Accountability no Brasil: os cidadão e seus meios institucionais de controles dos representantes. 2006. 243f. Tese (Doutorado em Ciência Política), Programa de Pós-Graduação em Ciências Política da Universidade de são Paulo, São Paulo, 2006.

PAULO LOPES. Câmara Municipal de Paulo Lopes. Resolução n. 02/94, Dispõe sobre o regimento interno da Câmara Municipal de Paulo Lopes/SC. Paulo Lopes: CMPL, 1994.

PEREIRA, Luiz Carlos Bresser. Estratégia e estrutura para um novo Estado. Revista do Serviço Público. Brasília, ano 48, n.1, p.5-25, jan./abr. 1997.

PINHO, José Antonio Gomes de; IGLESIAS, Diego Moura; SOUZA, Ana Carolina P. de. Portais de governo eletrônico de estados no Brasil: muita tecnologia e pouca democracia. In: ENCONTRO DA ANPAD, XXX, 2006, Salvador. Anais... Rio de Janeiro: ANPAD, 2006. 
PINHO, José Antonio Gomes de; SACRAMENTO, Ana Rita Silva. Accountability: já podemos traduzi-la para o português? In: ENCONTRO DE ADMINISTRAÇÃO PÚBLICA E GOVERNANÇA, III, 2008, Salvador. Anais... Rio de Janeiro: ANPAD, 2008.

PÓ, M. V.; ABRUCIO, F. L. A. Desenho e Funcionamento dos mecanismos de controle e accountability das agências reguladoras brasileiras: semelhanças e diferenças. Revista de Administração Pública. Rio de Janeiro, ano 40, n.4, p.67998, jul./ago. 2006.

PRZEWORSKI, Adam. Sobre o desenho do Estado: uma perspectiva agent $\mathbf{x}$ principal. In: BRESSER PEREIRA, Luiz Carlos; SPINK, Peter Kevin (Orgs.). Reforma do estado e administração pública gerencial. Rio de Janeiro: Fundação Getúlio Vargas, 1998.

RÊGO, Thaiseany de Freitas, BARBOSA, Eliedna de Sousa, ARAÚJO, Aneide Oliveira. A aplicação do custeio baseado em atividades no serviço de transporte escolar: um estudo de caso no Município de Sapé na Paraíba. In: CONGRESSO BRASILEIRO DE CUSTOS, XIV, 2007. João Pessoa. Anais... João Pessoa: ABC, 2007.

RIBEIRO FILHO, J. F. Uma análise contábil da Lei de Responsabilidade Fiscal sob a ótica da teoria da gestão econômica. Revista Brasileira de Contabilidade. Brasília, n. 132, p. 57-71, nov./dez. 2001.

SOUZA, Marcos Antônio de et al. A gestão pública por resultados e a avaliação de desempenho. In: CONGRESSO USP DE CONTROLADORIA E CONTABILIDADE, XIV, 2008. São Paulo. Anais... São Paulo: USP, 2008.

Submissão: 16/11/2009

Aceite: 16/12/2009 